\title{
PENGARUH PERSEPSI RISIKO, PRICE CONSCIOUSNESS, FAMILIARITY, PERSEPSI KUALITAS, DAN CITRA TOKO PADA MINAT BELI KONSUMEN
}

\author{
Dharmawan Santoso ${ }^{\left.1^{*}\right)}$, Mukhamad Najib², Jono Mintarto Munandar ${ }^{2}$ \\ ${ }^{1}$ Program Studi IImu Manajemen, Sekolah Pascasarjana Institut Pertanian Bogor, \\ Bogor 16680, Indonesia \\ 2 Departemen Manajemen, Fakultas Ekonomi dan Manajemen, Institut Pertanian Bogor, \\ Bogor 16680, Indonesia
}

*) E-mail: dharmawan.santoso93@gmail.com

\begin{abstract}
Abstrak
Penelitian ini bertujuan untuk mengidentifikasi perbedaan variabel laten (rak penyimpanan barang, familiarity, persepsi risiko, price consciousness, citra label khusus (private label), kualitas servis, dan persepsi kualitas) diantara jenis industri ritel; menganalisis pengaruh variabel laten; dan menganalisis pengaruh variabel laten terhadap minat beli konsumen terhadap food private label. Penelitian ini melibatkan 274 responden yang merupakan konsumen hipermarket, supermarket, dan minimarket di Kota Bogor yang dipilih dengan metode quota sampling. Uji Mann Whitney dan CB-SEM digunakan dalam analisis data, dengan tingkat kepercayaan 95,0 persen. Hasil yang diperoleh menunjukkan bahwa variabel citra toko, persepsi risiko, kualitas servis, familiarity, persepsi kualitas dan minat beli memiliki perbedaan antara konsumen hipermarket, supermarket, dan minimarket. Selain itu, uji pengaruh antarvariabel laten menemukan bahwa rak penyimpanan barang memengaruhi familiarity dan persepsi kualitas, kualitas servis memengaruhi citra private label; sedangkan citra private label dan familiarity memengaruhi persepsi risiko. Temuan menunjukkan adanya pengaruh secara signifikan hanya ditemukan pada citra toko yang memengaruhi minat beli.
\end{abstract}

Kata kunci: familiarity, food private label, minat beli, citra toko

\section{The Effect of Perceived Risk, Price Consciousness, Familiarity, Perceived Quality, and Store Image on Consumer Purchase Intention}

\begin{abstract}
This research aims to identify the difference of the latent variables (shelf space, familiarity, perceived risk, price consciousness, private label image, service quality, and perceived quality) among ritel industries; to analyze the influence among latent variables; and to analyze the effect of perceived risk, price cosnciousness, familiarity, perceived quality, and store image on consumer purchase intention on food private label. This research involved 274 respondent consist of hypermarket, supermarket, and minimarket consumer in Bogor City that were chosen by quota sampling method. Mann Whitney test and CB-SEM were used in data analysis, with confidence level is 95,0 percent. The results showed that store image, perceived risk, service quality, familiarity, perceived quality and purchase intention have differentiation among hypermarket, supermarket, and minimarket consumer. Moreover, the result also found that shelf space influenced familiarity and perceived quality; service quality influenced private label image, and then private label image and familiarity influenced perceived risk. The result also revealed a significant influence of store image on purchase intention.
\end{abstract}

Keywords: familiarity, food private label, purchase intention, store image

\section{PENDAHULUAN}

Trend private label kini telah berkembang luas di Indonesia. Berdasarkan survei yang dilakukan Euromonitor tahun 2011, konsumen Indonesia semakin terekspos untuk menerima produk-produk private label. Hal ini disebabkan oleh dua faktor. Faktor yang pertama yaitu terjadinya peningkatan permintaan dari konsumen berpendapatan rendah hingga menengah terhadap produk private label yang harganya lebih terjangkau. Faktor yang kedua yaitu meningkatnya jumlah outlet ritel modern di banyak kota di Indonesia serta banyaknya promosi yang cukup agresif dari peritel untuk mendorong jalur private label. Promosi yang agresif ini mendorong pengenalan dan penerimaan yang lebih besar terhadap produk private label oleh masyarakat (Matahari Departemen Store, 2012). Pertumbuhan produk private label juga dibarengi dengan pertumbuhan industri ritel modern di Indonesia. 
Hal ini disebabkan private label menjadi salah satu strategi yang digunakan oleh peritel untuk saling bersaing dalam meningkatkan pasar dan menyerap keuntungan lebih besar.

Industri ritel modern di Indonesia mengalami rata-rata pertumbuhan 10,8 persen pada tahun 2015 dengan pertumbuhan tertinggi terjadi di kelompok minimarket sebesar 11,0 persen dan supermarket/hipermarket sebesar 10,6 persen. Penjualan toko modern per kapita di Indonesia diperkirakan mencapai US\$ 60 dengan komposisi 56 persen di minimarket dan 44 persen di supermarket/hipermarket. Besar pasar industri minimarket di Indonesia mencapai sekitar Rp73 triliun dengan pertumbuhan rata-rata tahunan sebesar 13,5 persen untuk periode 2012-2015. Persaingan yang ketat juga terjadi di kelompok minimarket dan supermarket/hipermarket. Pada kelompok minimarket, Alfamart bersaing ketat dengan Indomaret. Sementara di kelompok supermarket/hipermarket, Hero bersaing ketat dengan Hipermarket (Dunia Industri, 2015).

Persaingan yang ketat diantara peritel dalam peluncuran produk private label dapat memberikan risiko kerugian bagi peritel. Konsumen dapat mengidentifikasi kehadiran produk private label diantara merek nasional di pasaran. Namun, persaingan ritel yang ketat menyebabkan jumlah proporsi produk private label sangat tinggi sehingga dapat berpotensi memberi kerugian (DBS Group Research, 2015). Produk private label yang beredar di pasaran biasanya memiliki harga yang murah dari produk merek nasional. Oleh karena itu, dengan banyaknya proporsi private label yang beredar akan membuat persaingan private label juga semakin ketat karena keuntungan utama yang diperoleh konsumen dengan membeli produk private label umumnya yaitu harga murah.

Produk private label yang diluncurkan peritel pada umumnya berupa Fast Moving Consumer Goods (FMCG). Hal ini disebabkan umumnya harga barang-barang tersebut relatif tidak mahal dan konsumen dapat mengonsumsinya dengan segera sehingga perputaran produk cukup cepat. Kantar Worldpanel Total National Indonesia (2015) mendefinisikan bahwa barang-barang yang mencangkup FMCG yaitu produk makanan, peralatan rumah tangga, dan perawatan tubuh. Pertumbuhan volume FMCG sepanjang tahun 2015 menurut Kantar Wolrdpanel Total National Indonesia (2015) yaitu kategori produk home care mengalami pertumbuhan volume sebesar 7 persen, produk perawatan diri mengalami pertumbuhan volume 2,5 persen, produk makanan sebesar $-4,9$ persen, produk makanan jenis susu -2,3 persen, dan minuman sebesar $-3,1$ persen.

Selanjutnya, data Kantar Total National Wolrdpanel Indonesia (2015) juga menyatakan bahwa produk makanan untuk makanan memiliki tingkat pertumbuhan terkecil yaitu $-4,9$ persen. Kondisi tersebut menunjukkan bahwa pada tahun 2015 masalah penurunan minat beli oleh konsumen Indonesia terhadap produk private label terjadi. Oleh karena itu, penting bagi peritel untuk mengetahui faktor-faktor apa yang memengaruhi minat beli konsumen terhadap produk private label.

Berdasarkan hasil Sensus Ekonomi Kota Bogor (BPS, 2016), sejak tahun 2010 hingga 2014 tingkat pertumbuhan ekonomi Kota Bogor terus mengalami kenaikan (Pemerintah Kota Bogor, 2016). Pada tahun 2013, Kota Bogor mengalami pertumbuhan ekonomi mencapai 6,1 persen. Perkembangan ekonomi Kota Bogor yang baik mendorong perkembangan ritel di Kota Bogor menjadi semakin banyak. Ritel yang berkembang di Kota Bogor tercatat sebagai top brand index 2013-2015 (Frontier Consulting Group, 2015). Oleh karena itu, kajian penelitian ini perlu dilakukan terhadap masyarakat Kota Bogor yang menjadi pengunjung ritel hipermarket, supermarket, dan minimarket.

Pada penelitian yang dilakukan Dursun et al. (2011) yang mengkaji pengaruh private label familarity, rak penyimpanan barang, persepsi kualitas dan persepsi risiko pada minat beli terhadap produk private label menunjukkan bahwa private label familiarity dan persepsi kualitas secara signifikan positif memengaruhi minat beli; serta persepsi risiko yang secara signifikan negatif memengaruhi minat beli. Selanjutnya, Dursun et al. (2011) juga menyatakan secara spesifik mengkaji private label produk susu, minyak zaitun, serbet, dan sabun cuci piring dengan lokasi penelitian di 5 supermarket di Turki. Penelitian $\mathrm{Wu}$ et al. (2010) juga mengkaji pengaruh citra toko, kualitas servis, citra private label, persepsi risiko, dan price consciousness terhadap minat beli. Penelitian tersebut menemukan bahwa citra toko dan persepsi risiko berpengaruh secara langsung terhadap minat beli. Wu et al. (2010) secara spesifik mengkaji private label berjenis produk obat-obatan dan produk kecantikan dengan lokasi penelitian di tokotoko obat di Taipei. Kualitas servis yang dikaji oleh Wu et al. (2011) merupakan penilaian konsumen terhadap kualitas pelayanan yang 
diberikan oleh toko ritel. Kualitas servis diukur berdasarkan 3 dimensi menurut Brady \& Cronin (2001) yaitu interaction quality (interaksi konsumen dengan karyawan), service environment quality (atmosfer dan lingkungan toko secara keseluruhan), dan outcome quality (jasa aktual yang diterima oleh konsumen).

Berdasarkan penelitian Dursun et al. (2011) dan Wu et al. (2011), faktor-faktor yang memengaruhi secara langsung terhadap minat beli yaitu familiarity, persepsi risiko, persepsi kualitas dan citra toko. Menurut hasil temuan Wu et al. (2011), price consciousness tidak memengaruhi minat pembelian. Namun hasil penelitian Jin \& Suh (2005) membuktikan bahwa price consciousness memengaruhi minat beli. Kontradiksi temuan penelitian terdahulu tersebut menjadi suatu hal yang menarik untuk diuji kembali pada penelitian ini. Oleh karenanya, penelitian ini membentuk model penelitian yang baru dengan menjadikan variabel familiarity, persepsi risiko, persepsi kualitas, citra toko dan price consciousness sebagai faktor yang diuji pengaruhnya secara langsung terhadap minat beli.

Beberapa hal yang membedakan penelitian ini dengan penelitian Dursun et al. (2011) dan Wu et al. (2011) yaitu produk yang dikaji yaitu private label bahan pangan olahan dan makanan. Selain itu, industri ritel yang diteliti berasal dari tiga kelompok yaitu hipermarket, supermarket dan minimarket. Dalam analisisnya, kajian ini melakukan uji tambahan Mann Whitney untuk mengetahui perbedaan persepsi konsumen antara hipermarket, supermarket, dan minimarket. Selain itu, penelitian ini mengombinasikan variabel eksogen yang berbeda dari dua penelitian terdahulu untuk dikaji lebih lanjut pengaruhnya terhadap minat beli konsumen.

Tujuan penelitian ini yaitu: 1) mengidentifikasi perbedaan variabel laten yang diteliti antara konsumen di hipermarket, supermarket dan minimarket; 2) menganalisis pengaruh rak penyimpanan barang terhadap familiarity dan persepsi kualitas; 3) menganalisis pengaruh persepsi risiko terhadap price consciousness; 4) menganalisis pengaruh citra private label terhadap persepsi risiko dan pengaruh kualitas servis terhadap citra private label; 5) menganalisis pengaruh familiarity terhadap persepsi kualitas; 6) menganalisis pengaruh familiarity terhadap persepsi risiko; dan 7) menganalisis pengaruh persepsi risiko, price consciousness, citra toko, persepsi kualitas dan familiarity terhadap minat beli.

\section{METODE PENELITIAN}

Lokasi penelitian ini dilakukan di 6 (enam) ritel berbeda di Kota Bogor yang terdiri dari 2 hipermarket, 2 supermarket, dan 2 minimarket. Pengambilan data berlangsung selama bulan Mei hingga Juni 2016. Desain penelitian yang digunakan yaitu cross sectional. Total responden yang digunakan sebanyak 274 orang. Responden yang dilibatkan yaitu pengunjung di keenam lokasi penelitian yang sedang membeli atau pernah menggunakan produk private label masing-masing ritel dalam jangka waktu 3 bulan terakhir.

Produk private label yang sedang atau pernah dikonsumsi harus berjenis makanan atau bahan pangan olahan seperti beras, minyak goreng, gula, kerupuk, bumbu dapur, sosis, snack dan sebagainya. Nama merek produk private label yang diteliti di masing-masing ritel yang menjadi lokasi penelitian adalah satu jenis produk. Teknik pemilihan contoh menggunakan metode quota sampling yaitu dengan menggunakan proporsi rata-rata pengunjung masing-masing dari keenam ritel tersebut dalam satu bulan.

Data primer diperoleh melalui teknik wawancara dan pengisian kuesioner oleh responden. Kualitas servis diukur dengan menggunakan indikator menurut Brady dan Cronin (2001) yaitu interaction quality, service environment quality, dan outcome quality. Citra private label diukur dengan menggunakan indikator menurut Vahie \& Paswan (2006) yaitu quality dan affective. Isi pertanyaannya mengenai jumlah rak pemajangan untuk private label dan kemudahan mencari produk private label yang diinginkan. Pada variabel rak penyimpanan barang indikator pertanyaan yang digunakan merupakan adopsi dari penelitian Dursun et al. (2011) yang selanjutnya dikembangkan oleh peneliti.

Selanjutnya butir pertanyaan untuk mengukur price consciousness diadopsi dari penelitian yang dilakukan Sinha \& Batra (1999), isi pertanyaan mengenai fokus harga murah, harga sebagai faktor utama dalam berbelanja, dan kebergantungan terhadap harga. Persepsi risiko diukur dengan menggunakan tiga indikator menurut Stone \& Gronhaug (1993) yaitu financial risk, functional risk dan body risk. Indikator pertanyaan familiarity diadopsi dari penelitian Vo \& Nguyen (2015). Isi pertanyaannya mengenai familiarity produk, kesanggupan mengingat produk, dan informasi yang pernah diperoleh mengenai produk. Selanjutnya, dasar pembentukan indikator 
pertanyaan persepsi kualitas adalah adopsi dari penelitian Richardson et al. (1996) yaitu kualitas rasa dan kualitas pengemasan/penampilan.

Indikator pertanyaan untuk mengukur minat beli diadopsi dari penelitian Knight \& Kim (2007) serta Bao et al. (2011), berisi pertanyaan mengenai kesediaan membeli di masa yang akan datang, minat untuk membeli lebih sering dan minat untuk mencoba produk. Indikator pertanyaan citra toko diadopsi dari penelitian Collins \& Lindley (2003) yang berisi pertanyaan mengenai kelengkapan dan kualitas produk yang dijual, atmosfer lingkungan belanja, dan pelayanan keseluruhan. Seluruh variabel yang diukur menggunakan jawaban skala Likert mulai dari $1=$ sangat tidak setuju; $2=$ tidak setuju; $3=$ raguragu; $4=$ setuju; dan $5=$ sangat setuju.

Data yang sudah melalui proses entering dan cleaning kemudian dianalisis dengan menggunakan analisis deksriptif, uji Mann Whitney, dan CB-SEM LISREL 8.3. Uji Mann Whitney dilakukan untuk melihat perbedaan variabel-variabel laten antara konsumen hipermarket, supermarket, dan minimarket, sedangkan CB-SEM LISREL 8.3 bertujuan untuk menguji pengaruh antarvariabel laten. Model penilitian yang akan diuji ditampilkan pada Gambar 1.

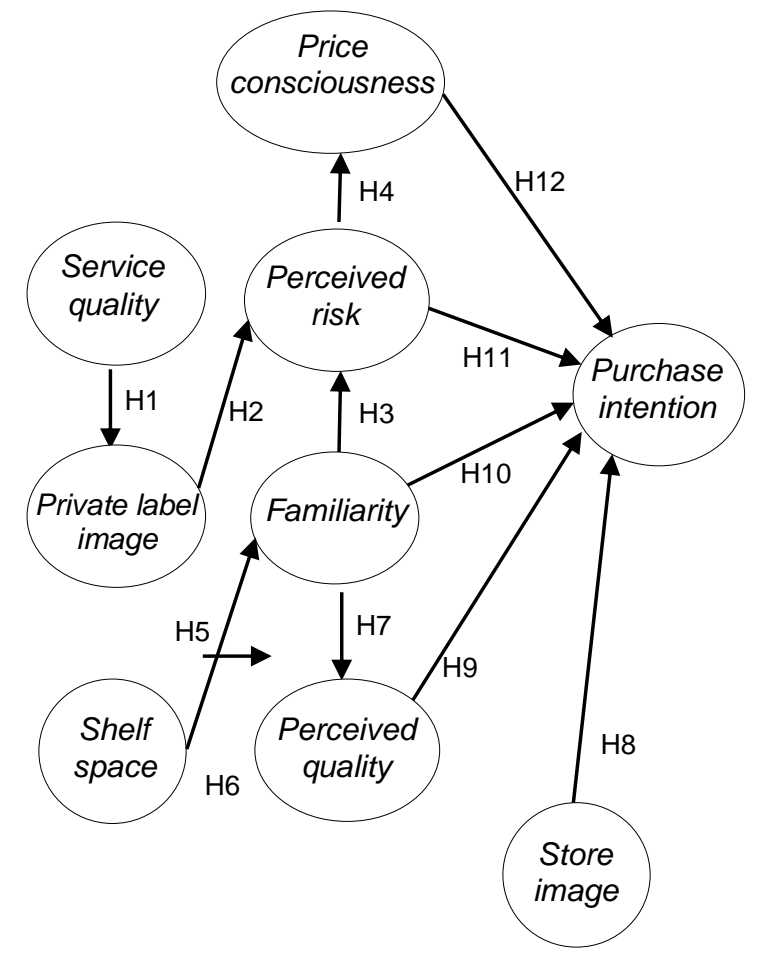

Gambar 1 Kerangka pemikiran penelitian

\section{HASIL}

\section{Karakteristik Responden}

Karakteristik responden penelitian ini terbagi menjadi tiga kelompok yaitu konsumen hipermarket sebanyak 102 orang, konsumen supermarket sebanyak 92 orang, dan konsumen minimarket sebanyak 80 orang. Berdasarkan jenis kelamin, persentase terbesar baik untuk kelompok hipemarket $(99,0 \%)$, supermarket $(96,7 \%)$, dan minimarket $(63,8 \%)$ adalah berjenis kelamin perempuan. Berdasarkan status menikah, sebanyak 61,8 persen responden hipermarket belum menikah, 72,8 persen responden supermarket telah menikah, dan sebanyak 53,8 persen responden minimarket belum menikah.

Persentase terbesar usia responden kelompok hipermarket $(39,0 \%)$ dan minimarket $(23,0 \%)$ antara 21 hingga 25 tahun. Sementara itu, hampir seperlima responden supermarket berusia antara 31 hingga 35 tahun (19,0\%). Berdasarkan tingkat pendidikan, persentase terbesar responden hipermarket $(55,0 \%)$, supermarket $(30,0 \%)$, dan minimarket $(38,0 \%)$ adalah SMA. Hampir tiga perempat responden hipermarket berstatus sebagai pelajar/ mahasiswa $(36,0 \%)$ dan pegawai swasta $(34,0 \%)$. Selanjutnya, sepertiga responden supermarket dan 26,0 persen responden minimarket bekerja sebagai pegawai swasta. Hasil analisis pendapatan per bulan menunjukkan hampir sepertiga $(30,0 \%)$ responden hipermarket berpendapatan antara Rp1.000.000,00 hingga Rp2.000.000,00. Selain itu, sebanyak seperempat responden supermarket $(25,0 \%)$ memiliki pendapatan antara Rp3.000.001,00 hingga Rp5.000.000,00. Sementara itu, pada kelompok minimarket, sebanyak 21,0 persen responden memiliki pendapatan antara Rp1.000.000,00 hingga Rp2.000.000,00. Selanjutnya, persentase terbesar responden di hipermarket $(33,0 \%)$, dan minimarket $(29,0 \%)$ memiliki pengeluaran total per bulan antara Rp1.000.000,00 hingga RP2.000.000,00. Sebanyak 26,0 persen responden supermarket memiliki pengeluaran per bulan sebesar Rp2.000.001,00 hingga Rp3.000.000,00.

\section{Hasil Uji Beda Variabel Laten}

Hasil penelitian seperti yang tersaji pada Tabel 1 yang dilakukan dengan uji Mann Whitney dengan tingkat $\alpha=5,0$ persen, menunjukkan bahwa citra toko antara hipermarket dan supermarket memiliki perbedaan yang signifikan. Hal ini dapat terjadi karena adanya 
perbedaan ukuran area belanja masingmasing ritel tersebut.

Tabel 1 Hasil uji Mann Whitney

\begin{tabular}{|c|c|c|c|}
\hline Variabel & $\begin{array}{l}\text { Perbedaan } \\
\text { kelompok }\end{array}$ & Sig. & Kesimpulan \\
\hline \multirow[t]{3}{*}{ Citra toko } & $\begin{array}{l}\text { hipermarket - } \\
\text { supermarket }\end{array}$ & 0,024 & Signifikan \\
\hline & $\begin{array}{l}\text { hipermarket - } \\
\text { minimarket }\end{array}$ & 0,001 & Signifikan \\
\hline & $\begin{array}{l}\text { supermarket - } \\
\text { minimarket }\end{array}$ & 0,131 & $\begin{array}{l}\text { Tidak } \\
\text { signifikan }\end{array}$ \\
\hline \multirow[t]{3}{*}{$\begin{array}{l}\text { Persepsi } \\
\text { risiko }\end{array}$} & $\begin{array}{l}\text { hipermarket - } \\
\text { supermarket }\end{array}$ & 0,008 & Signifikan \\
\hline & $\begin{array}{l}\text { hipermarket - } \\
\text { minimarket }\end{array}$ & 0,226 & $\begin{array}{l}\text { Tidak } \\
\text { signifikan }\end{array}$ \\
\hline & $\begin{array}{l}\text { supermarket - } \\
\text { minimarket }\end{array}$ & 0,000 & Signifikan \\
\hline \multirow[t]{3}{*}{$\begin{array}{l}\text { Kualitas } \\
\text { servis }\end{array}$} & $\begin{array}{l}\text { hipermarket - } \\
\text { supermarket }\end{array}$ & 0,603 & $\begin{array}{l}\text { Tidak } \\
\text { signifikan }\end{array}$ \\
\hline & $\begin{array}{l}\text { hipermarket - } \\
\text { minimarket }\end{array}$ & 0,033 & Signifikan \\
\hline & $\begin{array}{l}\text { supermarket - } \\
\text { minimarket }\end{array}$ & 0,094 & $\begin{array}{l}\text { Tidak } \\
\text { Signifikan }\end{array}$ \\
\hline \multirow{3}{*}{$\begin{array}{l}\text { Citra } \\
\text { private } \\
\text { label }\end{array}$} & $\begin{array}{l}\text { hipermarket - } \\
\text { supermarket }\end{array}$ & 0,266 & $\begin{array}{l}\text { Tidak } \\
\text { signifikan }\end{array}$ \\
\hline & $\begin{array}{l}\text { hipermarket - } \\
\text { minimarket }\end{array}$ & 0,719 & $\begin{array}{l}\text { Tidak } \\
\text { signifikan }\end{array}$ \\
\hline & $\begin{array}{l}\text { supermarket - } \\
\text { minimarket }\end{array}$ & 0,486 & $\begin{array}{l}\text { Tidak } \\
\text { signifikan }\end{array}$ \\
\hline \multirow[t]{3}{*}{$\begin{array}{l}\text { Price cons- } \\
\text { ciousness }\end{array}$} & $\begin{array}{l}\text { hipermarket - } \\
\text { supermarket }\end{array}$ & 0,629 & $\begin{array}{l}\text { Tidak } \\
\text { signifikan }\end{array}$ \\
\hline & $\begin{array}{l}\text { hipermarket - } \\
\text { minimarket }\end{array}$ & 0,531 & $\begin{array}{l}\text { Tidak } \\
\text { signifikan }\end{array}$ \\
\hline & $\begin{array}{l}\text { supermarket - } \\
\text { minimarket }\end{array}$ & 0,267 & $\begin{array}{l}\text { Tidak } \\
\text { signifikan }\end{array}$ \\
\hline \multirow[t]{3}{*}{ Familiarity } & $\begin{array}{l}\text { hipermarket - } \\
\text { supermarket }\end{array}$ & 0,090 & $\begin{array}{l}\text { Tidak } \\
\text { signifikan }\end{array}$ \\
\hline & $\begin{array}{l}\text { hipermarket - } \\
\text { minimarket }\end{array}$ & 0,000 & Signifikan \\
\hline & $\begin{array}{l}\text { supermarket - } \\
\text { minimarket }\end{array}$ & 0,018 & Signifikan \\
\hline \multirow[t]{3}{*}{$\begin{array}{l}\text { Persepsi } \\
\text { kualitas }\end{array}$} & $\begin{array}{l}\text { hipermarket - } \\
\text { supermarket }\end{array}$ & 0,184 & $\begin{array}{l}\text { Tidak } \\
\text { signifikan }\end{array}$ \\
\hline & $\begin{array}{l}\text { hipermarket - } \\
\text { minimarket }\end{array}$ & 0,052 & $\begin{array}{l}\text { Tidak } \\
\text { Signifikan }\end{array}$ \\
\hline & $\begin{array}{l}\text { supermarket - } \\
\text { minimarket }\end{array}$ & 0,001 & Signifikan \\
\hline \multirow{3}{*}{$\begin{array}{l}\text { Rak } \\
\text { penyimpan } \\
\text { an barang }\end{array}$} & $\begin{array}{l}\text { hipermarket - } \\
\text { supermarket }\end{array}$ & 0,438 & $\begin{array}{l}\text { Tidak } \\
\text { signifikan }\end{array}$ \\
\hline & $\begin{array}{l}\text { hipermarket - } \\
\text { minimarket }\end{array}$ & 0,481 & $\begin{array}{l}\text { Tidak } \\
\text { signifikan }\end{array}$ \\
\hline & $\begin{array}{l}\text { supermarket - } \\
\text { minimarket }\end{array}$ & 0,945 & $\begin{array}{l}\text { Tidak } \\
\text { signifikan }\end{array}$ \\
\hline \multirow[t]{3}{*}{$\begin{array}{l}\text { Minat } \\
\text { pembelian }\end{array}$} & $\begin{array}{l}\text { hipermarket - } \\
\text { supermarket }\end{array}$ & 0,892 & $\begin{array}{l}\text { Tidak } \\
\text { signifikan }\end{array}$ \\
\hline & $\begin{array}{l}\text { hipermarket - } \\
\text { minimarket }\end{array}$ & 0,004 & Signifikan \\
\hline & $\begin{array}{l}\text { supermarket - } \\
\text { minimarket }\end{array}$ & 0,013 & Signifikan \\
\hline
\end{tabular}

Selain itu, juga terdapat perbedaan dari segi kelengkapan jenis produk yang dijual. Dua alasan tersebut berlaku sama untuk menjelaskan perbedaan citra toko antara konsumen hipermarket dan minimarket yang memang cukup signifikan dari segi ukuran toko dan kelengkapan produk barang. Sementara itu, konsumen supermarket dan minimarket relatif tidak berbeda dalam hal citra toko.

Perbedaan yang signifikan juga ditunjukkan pada variabel persepsi risiko antara konsumen hipermarket dan supermarket dan antara konsumen supermarket dan minimarket. Hal ini disebabkan adanya perbedaan citra toko antara hipermarket dan supermarket dan perbedaan familiarity antara supermarket dan minimarket. Selanjutnya, trust antara hipermarket dan minimarket memiliki perbedaan yang signifikan. Familiarity antara supermarket dan minimarket juga memiliki perbedaan yang signifikan. Hal ini dapat terjadi akibat adanya pengaruh banyaknya jenis produk private label yang dimiliki serta perbedaan ukuran toko. Pada kategori hipermarket dan supermarket, toko cenderung memiliki jenis produk private label yang lebih banyak dibandingkan minimarket. Ukuran tempat hipermarket dan supermarket relatif lebih besar sehingga memungkinkan untuk lebih banyak meletakan produk private label di berbagai tempat.

Hasil uji Mann Whitney juga menunjukkan bahwa kualitas servis antara hipermarket dan minimarket memiliki perbedaan yang signifikan. Hal ini diduga karena adanya perbedaan jumlah karyawan yang dimiliki, luas, dan dekorasi ruang antara hipermarket dengan minimarket. Pada umumnya toko hipermarket memiliki karyawan yang lebih banyak di area belanja sehingga interaksi yang terjadi antara konsumen dengan pegawai toko tentu lebih banyak. Selain itu, toko hipermarket memiliki area pembelanjaan yang lebih luas dibandingkan dengan minimarket. Hipermarket juga diduga memiliki dekorasi lebih baik dibandingkan dengan minimarket.

Perbedaan signifikan juga ditemukan pada persepsi kualitas antara supermarket dan minimarket. Temuan ini dapat disebabkan oleh perbedaan kelompok konsumen. Perbedaan sensitifitas konsumen terhadap harga juga menjadi faktor yang utama. Hal ini dapat diketahui dari karakteristik responden yang menunjukkan bahwa adanya perbedaan total pengeluaran per bulan antara responden supermarket dan minimarket. Perbedaan pengeluaran ini dapat menunjukkan sensitifitas 
harga konsumen yang dapat memengaruhi perbedaan pandangan mengenai kualitas produk.

Hasil analisis juga menemukan perbedaan yang signifikan antara minat beli antara hipermarket dan minimarket. Minat beli antara supermarket dan minimarket juga memiliki perbedaan yang signifikan. Hal ini dapat disebabkan oleh masih sedikitnya jenis produk makanan private label yang ditawarkan oleh minimarket. Sementara itu, jenis produk private label yang ditawarkan oleh hipermarket dan supermarket relatif lebih banyak dan luas.

\section{Analisis Pengaruh Variabel Laten}

Uji covariance base-SEM digunakan untuk menganalisis faktor-faktor yang memengaruhi minat beli konsumen terhadap produk food private label. Tahap pertama yang perlu dilakukan dalam analisis SEM yaitu menguji kebaikan model (goodness of fit). Dalam pengujian tersebut, terdapat beberapa asumsi yang perlu dipenuhi agar model dapat dinyatakan baik yaitu RMR (Root Mean Square Residual), RMSEA (Root Mean square Error of Approximation), AGFI (Adjusted Goodness of Fit Index), NFI (Normed Fit Index), dan CFI (Comparative Fit Index).

Berdasarkan Tabel 2, dapat diketahui bahwa semua asumsi (RMR, RMSEA, AGFI, NFI, $\mathrm{CFI}$ memenuhi batas cut-off-value sehingga dapat disimpulkan bahwa model SEM yang dianalisis telah layak. Langkah selanjutnya yaitu melihat seberapa kuat indikator masingmasing variabel laten memiliki pengaruh terhadap variabel latennya. Identifikasi ini dapat dilakukan dengan melihat nilai koefisien atau loading factor antara indikator terhadap variabel latennya. Diagram hasil estimasi loading factor ditampilkan pada Gambar 2.

Gambar 2 menunjukkan bahwa SQ2 (service environtment quality) merupakan indikator yang paling berpengaruh terhadap variabel kualitas servis dengan nilai koefisien sebesar 0,54 . Selanjutnya, indikator SS2 (kemudahan menemukan produk private label yang ingin dicari karena banyaknya rak pemajangan untuk produk tersebut) paling berpengaruh terhadap rak penyimpanan barang dengan nilai koefisien sebesar 0,52. Selain itu, indikator PR3 (body risk) paling berpengaruh terhadap variabel persepsi risiko dengan nilai koefisien 0,38. Hasil penelitian juga menemukan indikator PBI2 (affective) merupakan indikator yang paling memengaruhi citra private label dengan nilai koefisien 0,92.
Tabel 2 Hasil uji goodness of fit model

\begin{tabular}{llll}
\hline $\begin{array}{c}\text { Goodness- } \\
\text { of-Fit }\end{array}$ & $\begin{array}{c}\text { Cutt-off- } \\
\text { Value }\end{array}$ & Hasil & Keterangan \\
\hline RMR & $\leq 0,1$ & 0,073 & Good Fit \\
RMSEA & $\leq 0,08$ & 0,061 & Good Fit \\
AGFI & $\geq 0,90$ & 0,94 & Good Fit \\
NFI & $\geq 0,95$ & 0,95 & Good Fit \\
CFI & $\geq 0,90$ & 0,97 & Good Fit \\
\hline
\end{tabular}

Indikator PC1 (fokus harga murah) merupakan indikator yang paling memengaruhi price consciousness dengan nilai koefisien sebesar 0,88 . Selanjutnya, indikator F2 (ingatan terhadap produk private label) paling berpengaruh terhadap variabel familiarity dengan nilai koefisien sebesar 0,82 . Indikator PQ1 adalah indikator yang paling memengaruhi persepsi kualitas dengan nilai koefisien 0,88. Indikator SI1 paling memengaruhi variabel citra toko dengan nilai koefisien 0,79. Indikator PI1 (minat untuk membeli di masa yang akan datang) memiliki nilai koefisien terbesar $(0,93)$ sehingga paling berpengaruh terhadap minat beli.

Langkah berikutnya yaitu mengidentifikasi pengaruh antara variabel laten dengan melihat hasil uji t untuk menentukan apakah hipotesis diterima atau ditolak. Nilai $\alpha$ yang digunakan yaitu 5,0 persen sehingga t-tabel yang menjadi acuan sebesar 1,96. Berdasarkan Tabel 3 dapat diketahui bahwa dari 12 hipotesis yang diajukan dalam penelitian ini hanya 6 hipotesis saja yang diterima. Temuan tersebut juga menunjukkan bahwa dari 5 variabel yang diuji pengaruhnya secara langsung terhadap minat beli konsumen, variabel citra toko merupakan variabel yang paling memengaruhi minat beli konsumen.

Hasil penelitian menemukan bahwa kualitas servis berpengaruh signifikan positif terhadap citra private label. Selanjutnya, citra private label juga berpengaruh signifikan positif terhadap persepsi risiko. Variabel familiarity berpengaruh signifikan positif terhadap persepsi risiko. Hasil analisis path juga menemukan bahwa rak penyimpanan barang berpengaruh signifikan positif terhadap familiarity dan persepsi kualitas. Sementara itu, persepsi risiko tidak bepengaruh signifikan terhadap price consciousness dan minat pembelian. Variabel familiarity tidak berpengaruh signifikan terhadap persepsi kualitas dan minat pembelian. Selain itu, persepsi kualitas tidak berpengaruh signifikan terhadap minat beli. Hasil yang tersaji pada Tabel 3 menemukan bahwa persepsi risiko tidak memengaruhi price consciousness dan minat beli. 


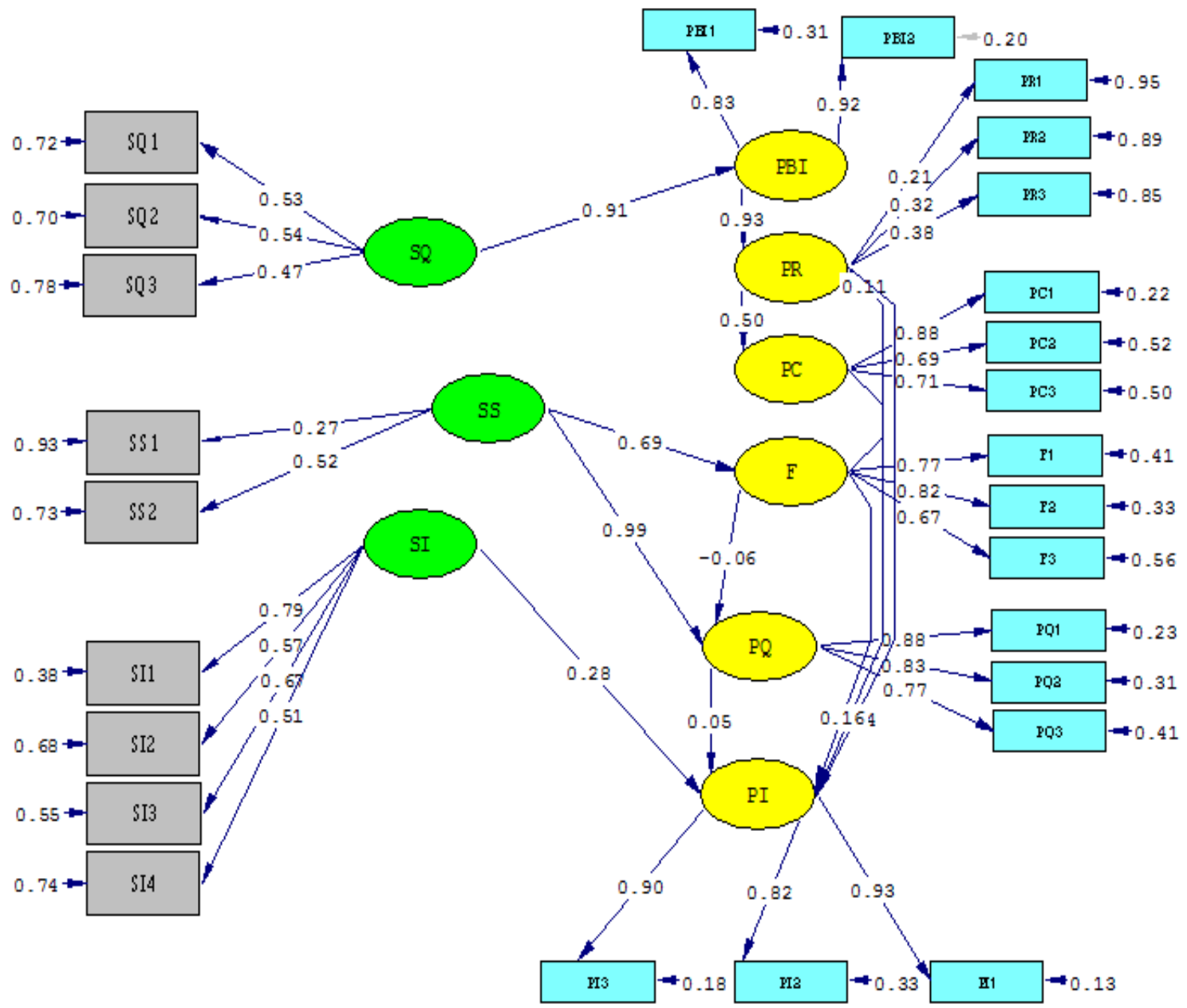

Chi-Square $=504.42, \mathrm{df}=250, \mathrm{P}$-value $=0.00000, \mathrm{RMSEA}=0.061$

Gambar 2 Diagram hasil estimasi loading factor

Selain itu, hasil penelitian juga menemukan bahwa familiarity konsumen terhadap produk private label juga tidak memengaruhi secara nyata terhadap persepsi kualitas. Bahkan penelitian ini juga menemukan bahwa familiarity dan persepsi kualitas tidak memengaruhi minat beli konsumen terhadap produk private label yang ada di industri ritel (Tabel 3).

Seperti yang telah dijelaskan sebelumnya, hasil yang tersaji pada Tabel 3 menemukan bahwa minat beli konsumen terhadap produk private label pada penelitian ini hanya dipengaruhi oleh citra toko yang merujuk pada citra konsumen terhadap toko ritel tempat konsumen membeli. Selanjutnya, variabel laten lain, baik itu persepsi kualitas, familiarity, persepsi risiko, maupun price consciousness tidak ditemukan memberi pengaruh signifikan terhadap minat beli. Selanjutnya, pada Gambar 3, secara lengkap disajikan diagram path SEM untuk nilai $t$ dalam pengujian hipotesis penelitian.
Tabel 3 Hasil nilai t-hitung antarvariabel laten

\begin{tabular}{|c|c|c|c|}
\hline $\begin{array}{l}\text { Hipo- } \\
\text { tesis }\end{array}$ & Path & Nilai Kesimpular & $\begin{array}{l}\text { Keputusan } \\
\text { hipotesis }\end{array}$ \\
\hline$\overline{\mathrm{H} 1}$ & $\begin{array}{l}\text { Kualitas servis } \rightarrow \text { citra } \\
\text { private label }\end{array}$ & $\begin{array}{l}\text { 24,0 Signifikan } \\
\text { positif }\end{array}$ & Diterima \\
\hline $\mathrm{H} 2$ & $\begin{array}{l}\text { Citra private label } \rightarrow \\
\text { persepsi risiko }\end{array}$ & $\begin{array}{l}\text { 23,6 Signifikan } \\
\text { positif }\end{array}$ & Diterima \\
\hline H3 & $\begin{array}{l}\text { Familiarity } \rightarrow \text { persepsi } \\
\text { risiko }\end{array}$ & $\begin{array}{l}\text { 4,4 Signifikan } \\
\text { positif }\end{array}$ & Diterima \\
\hline $\mathrm{H} 4$ & $\begin{array}{l}\text { Persepsi risiko } \rightarrow \text { price } \\
\text { consciousness }\end{array}$ & $\begin{array}{l}\text { 1,7 Tidak } \\
\text { signifikan }\end{array}$ & Ditolak \\
\hline H5 & $\begin{array}{l}\text { Rak penyimpanan } \\
\text { barang } \rightarrow \text { familiarity }\end{array}$ & $\begin{array}{l}\text { 22,9 Signifikan } \\
\text { positif }\end{array}$ & Diterima \\
\hline $\mathrm{H} 6$ & $\begin{array}{l}\text { Rak penyimpanan } \\
\text { barang } \rightarrow \text { persepsi } \\
\text { kualitas }\end{array}$ & $\begin{array}{l}\text { 10,5 Signifikan } \\
\text { positif }\end{array}$ & Diterima \\
\hline $\mathrm{H} 7$ & $\begin{array}{l}\text { Familiarity } \rightarrow \text { persepsi } \\
\text { kualitas }\end{array}$ & $\begin{array}{l}-0,4 \text { Tidak } \\
\text { signifikan }\end{array}$ & Ditolak \\
\hline H8 & $\begin{array}{l}\text { Citra toko } \rightarrow \text { minat } \\
\text { pembelian }\end{array}$ & $\begin{array}{l}\text { 3,5 Signifikan } \\
\text { positif }\end{array}$ & Diterima \\
\hline $\mathrm{H} 9$ & $\begin{array}{l}\text { Persepsi kualitas } \rightarrow \\
\text { minat pembelian }\end{array}$ & $\begin{array}{l}\text { 0,3 Tidak } \\
\text { signifikan }\end{array}$ & Ditolak \\
\hline $\mathrm{H} 10$ & $\begin{array}{l}\text { Familiarity } \rightarrow \text { minat } \\
\text { pembelian }\end{array}$ & $\begin{array}{l}\text { 1,8 Tidak } \\
\text { signifikan }\end{array}$ & Ditolak \\
\hline $\mathrm{H} 11$ & $\begin{array}{l}\text { Persepsi risiko } \rightarrow \text { minat } \\
\text { pembelian }\end{array}$ & $\begin{array}{l}\text { 0,8 Tidak } \\
\text { signifikan }\end{array}$ & Ditolak \\
\hline $\mathrm{H} 12$ & $\begin{array}{l}\text { Price consciousness } \rightarrow \\
\text { minat pembelian }\end{array}$ & $\begin{array}{l}-0,5 \text { Tidak } \\
\text { signifikan }\end{array}$ & $k$ \\
\hline
\end{tabular}




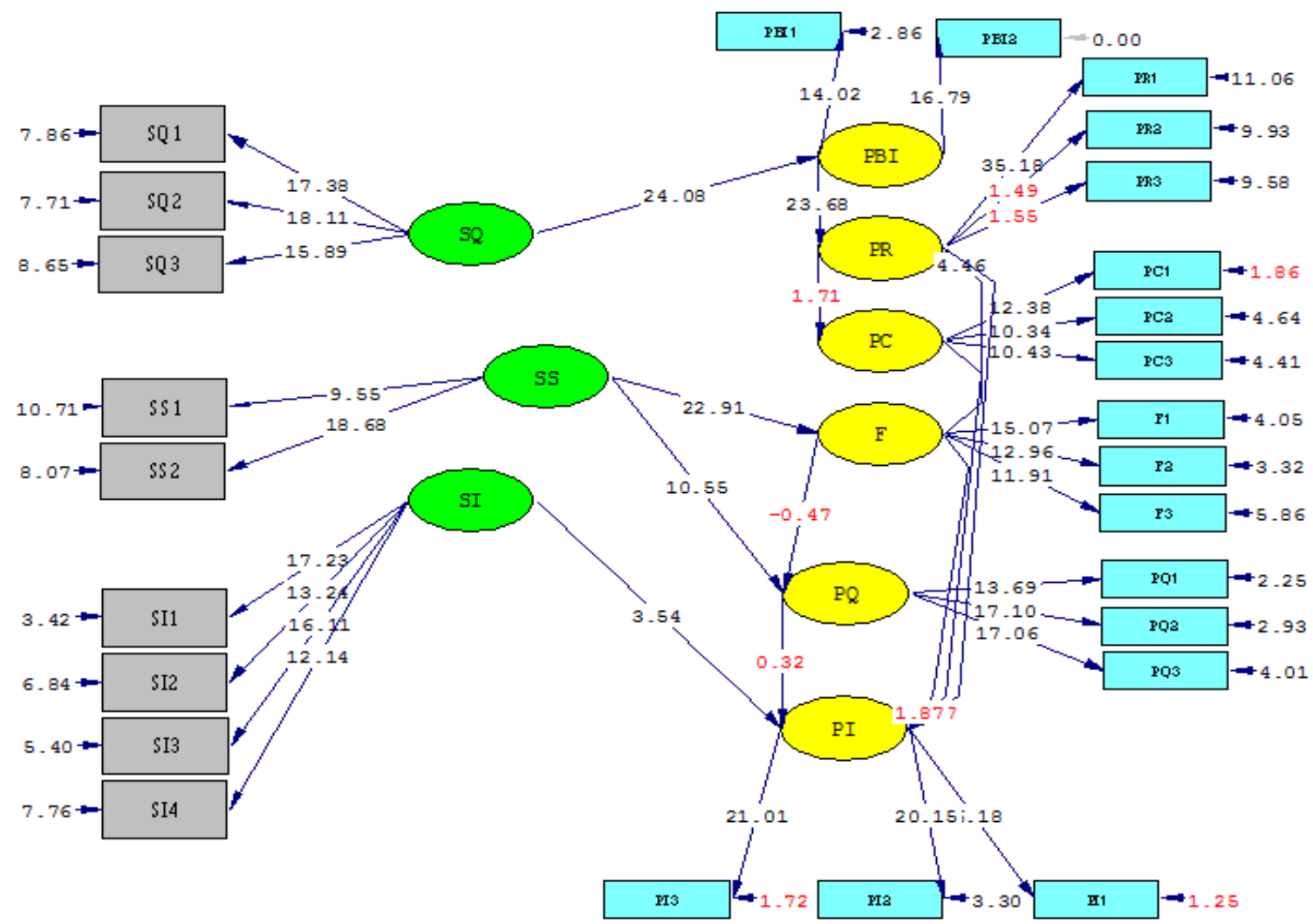

Chi-Square $=504.42, d f=250, P$-value $=0.00000$, RMSEA $=0.061$

\section{Gambar 3 Diagram hasil uji T}

\section{PEMBAHASAN}

\section{Pengaruh Persepsi risiko pada Minat Beli Konsumen}

Hasil penelitian menunjukkan bahwa persepsi risiko tidak memiliki pengaruh yang signifikan terhadap minat pembelian. Nilai koefisien dan nilai $t$ yang dihasilkan yaitu 0,54 dan 0,83 . Hasil temuan ini berbeda dengan temuan Arslan et al. (2013) serta Liljander et al. (2009) yang menyatakan bahwa persepsi risiko memengaruhi minat beli konsumen. Hal ini dapat disebabkan adanya perbedaan harga yang cukup signifikan antara produk makanan private label dengan produk merek nasional sehingga produk private label memiliki daya saing dengan produk merek nasional melalui harga yang kompetitif. Oleh karena itu, banyak konsumen berminat dan mempertimbangkan membeli produk private label didasarkan pada harganya yang murah. Selain itu, sebagian besar konsumen di Indonesia merupakan konsumen yang cukup sensitif terhadap harga. Berdasarkan temuan ini terdapat beberapa hal yang bisa dipertimbangkan oleh pembuat kebijakan seperti tetap mengawasi dan menetapkan standar mutu produk yang baik sehingga konsumen tidak hanya mendapatkan keuntungan harga murah dari produk yang dipasarkan produsen, namun juga mendapatkan kualitas yang terjaga baik. Hal yang bisa dipertimbangkan oleh konsumen yaitu, kualitas produk, pengalaman mengonsumsi dan saran dari relasi masingmasing tentang produk sehingga konsumen juga tetap dapat memperoleh mutu terbaik dari memilih produk dengan tepat.

\section{Pengaruh Price Consciousness pada Minat Beli Konsumen}

Price consciousness tidak berpengaruh terhadap consumer minat pembelian dengan nilai koefisien $-0,036$ dan nilai $t$ adalah -0,57 . Hal ini dapat disebabkan oleh beberapa konsumen yang merasa bahwa perbedaan harga antara produk private label dan produk merek nasional tidak terlalu jauh sehingga terkadang ada konsumen yang lebih memilih produk merek nasional. Oleh karena itu, penting sekali bagi peritel untuk mampu memberikan diskon-diskon yang menarik di waktu yang tepat misalnya saat weekend agar mampu bersaing dengan produk merek nasional dalam merebut hati pelanggan yang lebih sensitif terhadap harga. Price consciousness didefinisikan sebagai 
keengganan konsumen membayar harga yang lebih tinggi untuk sebuah produk, dengan kata lain konsumen fokus pada harga yang lebih rendah (Lichtenstein et al., 1993)

\section{Pengaruh Citra toko pada Minat Beli Konsumen}

Hasil analisis data menunjukkan bahwa citra toko memiliki pengaruh yang signifikan dan positif terhadap minat pembelian. Nilai koefisien dan nilat $t$ yang dihasilkan yaitu 0,28 dan 3,54. Citra toko terbentuk atas kombinasi antara atribut-atribut toko seperti lingkungan belanja, pelayanan toko, kualitas-kualitas barang yang dijual, dan keanekaragaman produk yang dijual (Ailawadi \& Keller 2004; Zimmer \& Golden 1988). Produk private label yang dipasarkan oleh ritel memiliki asosiasi yang kuat terhadap citra ritel tersebut. Citra toko yang baik tentu juga akan menciptakan citra yang baik juga pada produk milik toko tersebut, terutama jika nama merek produk memiliki nama yang sama dengan toko. Oleh karena itu, penelitian ini mendukung penelitian sebelumnya bahwa citra toko yang semakin positif maka minat beli juga akan semakin positif (Bao et al., 2011; Wu et al., 2011; Dodds et al., 1991; Grewal et al., 1998).

\section{Pengaruh Persepsi kualitas pada Minat Beli Konsumen}

Persepsi kualitas tidak berpengaruh signifikan terhadap consumer minat pembelian. Nilai koefisien dan nilai t yang dihasilkan yaitu 0,05 dan 0,32 . Hasil temuan ini menunjukkan minat beli konsumen terhadap produk private label tidak dipengaruhi oleh persepsi konsumen akan kualitas produk private label dan sesuai dengan temuan Arslan et al. (2013). Mayoritas konsumen melakukan pembelian pada produk private label karena harganya sangat miring jika dibandingkan produk-produk merek nasional atau umum. Meskipun persepsi kualitas ditemukan tidak memengaruhi minat beli pada kategori makanan, namun terdapat kemungkinan bahwa persepsi kualitas berpengaruh pada minat pembelian untuk kategori produk yang lain (Glynn \& Chen 2009). Oleh karena itu, untuk peneliti di masa yang akan datang, dapat melakukan kajian minat beli konsumen untuk kategori produk yang lain.

\section{Pengaruh Familiarity pada Minat Beli Konsumen}

Berdasarkan hasil analisis diketahui bahwa familiarity tidak memiliki pengaruh yang signifikan terhadap minat beli konsumen dengan nilai koefisien 0,16 . Namun, nilai thitung yang dihasilkan sebesar 1,87 menunjukkan bahwa familarity tetap merupakan faktor yang cukup penting untuk diperhatikan. Menurut Alba dan Hutchinson (1987), familiarity adalah banyaknya pengalaman yang telah dikumpulkan oleh konsumen terkait dengan suatu produk atau merek. Hal ini menunjukkan bahwa seberapa akrab dan seberapa besar pengetahuan konsumen mengetahui suatu produk. Jika konsumen pernah mendapatkan informasi tentang produk private label maka hal tersebut akan membuat konsumen lebih akrab dengan suatu produk private label. Jika konsumen pernah mendengar dan merasa bahwa suatu produk cukup familiar dan telah cukup lama berada di pasaran maka ada daya tarik tersendiri bagi konsumen untuk lebih berani membeli produk private label tersebut, terutama jika konsumen pernah menggunakannya secara langsung di masa lampau.

Beberapa hal yang bisa dilakukan oleh peritel yaitu lebih banyak memasang informasi mengenai produk-produk private label di area perbelanjaan toko. Selain itu, perlu selalu diberitakan mengenai keberadaan dan informasi diskon produk private label dengan menggunakan audio system di area belanja. Selain itu, karyawan perlu menguasai secara sempurna informasi mengenai produk private label agar dapat memberi penjelasan kepada pengunjung yang bertanya serta pegawai kasir yang selalu menawarkan produk private label kepada pengunjung seraya sambil melakukan transaksi pembayaran konsumen.

\section{Pengaruh Rak penyimpanan barang pada Familiarity}

Penelitian ini menemukan bahwa rak penyimpanan barang memiliki pengaruh yang signifikan terhadap familiarity. Nilai koefisien dan nilai $t$ yang dihasilkan yaitu 0,69 dan 22,91 . Jika semakin banyak tempat dan ruang pemajangan yang disediakan khusus untuk produk pribadi milik ritel maka akan menambah tingkat familiarity konsumen dengan produk private label. Peritel dapat memanfatkan ruang pemajangan untuk posisi yang menguntungkan produk private label mereka sendiri. Misalnya, produk private label diletakan di rak paling atas tempat konsumen dapat melihat pertama kali ketika mencari kategori produk yang diinginkan. Peritel juga dapat menyajikan produk private label di dekat kasir. Selain itu, peritel juga dapat 
menambahkan informasi yang dikemas dalam bentuk unik pada rak pemajangan mengenai produk private label mereka. Brown \& Lee (1996) menyatakan bahwa rak penyimpanan barang dapat dipertimbangkan sebagai bentuk advertising, meletakan produk menjadi top of consumer minds, dan memberi kesan pada suatu produk tentang level popularitasnya.

\section{Pengaruh Rak penyimpanan barang pada Persepsi kualitas}

Hasil penelitian menemukan bahwa rak penyimpanan barang berpengaruh signifikan positif terhadap persepsi kualitas. Hasil ini sejalan dengan temuan Dursun et al. (2011) bahwa peritel perlu memanfaatkan dan mengoptimalkan rak penyimpanan barang yang dimiliki untuk produk private label yang dijual. Namun peritel juga harus berhati-hati dalam menyiapkan tempat pemajangan dan box tempat pemajangan untuk private label yang dijual. Peritel harus memajang produk private label dengan rapi dan baik serta nampak cantik. Jika hanya meletakan banyak rak pemajangan dan meletakan berbagai tempat namun tidak rapi dan cantik serta tidak dikontrol secara berkala maka tentu akan menimbulkan kesan kualitas yang menurun. Sementara itu, produk merek nasional yang walaupun sedikit ruang pemajangannya menjadi terlihat lebih ekslusif dibandingkan produk private label.

\section{Pengaruh Persepsi risiko pada Price Consciousness}

Hasil menunjukkan bahwa persepsi risiko tidak berpengaruh terhadap price consciousness dengan nilai koefisien 0,50 dan 1,71. Temuan ini berbeda dengan temuan Wu et al. (2010). Perbedaan temuan ini dapat disebabkan adanya perbedaan budaya konsumen antarnegara serta perbedaan produk yang diteliti mengingat $\mathrm{Wu}$ et al. (2010) meneliti produk obat-obatan dan produk kecantikan.

\section{Pengaruh Citra private label pada Persepsi risiko}

Hasil menunjukkan bahwa citra private label berpengaruh signifikan terhadap persepsi risiko. Nilai koefisien dan nilai t yang dihasilkan yaitu 0,93 dan 23,68 . Hal ini dapat dipahami bahwa semakin baik citra produk private label dalam benak konsumen maka persepsi risiko yang ada di dalam benak konsumen terhadap produk private label juga semakin berkurang. Temuan ini sesuai dengan penelitian $\mathrm{Wu}$ et al. (2011). Hal ini akan menyebabkan semakin berkurangnya keraguan pada benak konsumen untuk lebih memilih produk private label. Produsen menjaga citra produk dapat dilakukan dengan terus menjaga kualitas tanpa ada cacat. Peritel perlu mempelajari para merek nasional yang menjadi pesaing dan melakukan pendekatan dalam menyamakan kualitas dengan merek-merek nasional tersebut.

\section{Pengaruh Kualitas servis pada Citra private label}

Kualitas servis memiliki pengaruh signifikan positif terhadap citra private label. Nilai koefisien dan nilai $t$ yang dihasilkan yaitu 0,91 dan 24,08. Temuan ini menunjukkan bahwa kualitas jasa yang diberikan toko meliputi kualitas pelayanan toko dan lingkungan toko memengaruhi pandangan konsumen terhadap citra produk private label toko tersebut. Hasil ini sesuai dengan temuan $\mathrm{Wu}$ et al. (2011) yang menyatakan bahwa kualitas servis berpengaruh signifikan terhadap citra private label. Oleh karena itu, kualitas jasa yang ditawarkan sangat penting untuk memengaruhi penilaian konsumen terhadap produk private label, sesuai dengan teori bahwa untuk produk private label yang tidak biasa bagi konsumen, konsumen akan mempertimbangkan image produk tersebut melalui kualitas jasa yang ditawarkan oleh toko (Agrawal et al., 1996; Dhar \& Hock, 1997). Kualitas jasa yang baik akan menyebabkan citra suatu produk private label dalam benak konsumen menjadi semakin positif karena dipengaruhi kepuasan konsumen yang semakin meningkat terhadap toko tersebut. (Anderson et al., 1994; Carrilat et al., 2009; Parasuraman et al., 1985).

\section{Pengaruh Familiarity pada Persepsi kualitas}

Hasil analisis menunjukkan bahwa familiarity tidak berpengaruh signifikan terhada persepsi kualitas dengan nilai koefisien $-0,057$ dan nilai $\mathrm{t}-0,47$. Temuan ini menunjukkan bahwa meskipun konsumen mengetahui informasi dan pernah mendengar mengenai suatu produk makanan private label, hal tersebut belum tentu akan langsung meningkatkan persepsi konsumen akan kualitas produk tersebut. Temuan yang didapatkan cukup berbeda dengan temuan dari Dursun et al. (2011) dan Sheau et al. (2012). Hal ini juga dapat disebabkan adanya perbedaan kategori produk yang dikaji.

Selanjutnya, familiarity berpengaruh signifikan terhadap persepsi risiko dengan nilai koefesien 
dan nilai t yang dihasilkan yaitu 0,11 dan 4,46. Hal ini menunjukkan bahwa jika konsumen telah memiliki informasi mengenai produk private label maka dapat mengurangi rasa keraguan dan persepsi adanya risiko mengenai produk private label. Toko ritel dapat menyediakan SPG yang menawarkan tester mengenai produk private label mereka lebih banyak lagi dan megundang konsumen dengan menawarkan diskon.

\section{SIMPULAN DAN SARAN}

Hasil analisis menunjukan bahwa variabel citra toko, persepsi risiko, kualitas servis, familiarity, persepsi kualitas dan minat pembelian dipersepsikan berbeda antara konsumen hipermarket, supermarket, dan minimarket. Sementara itu, variabel citra private label, price consciousness, dan rak penyimpanan barang tidak dipersepsikan berbeda antara konsumen hipermarket, supermarket, dan minimarket. Hasil analisis yang menunjukkan bahwa dari lima variabel yang diuji pengaruhnya terhadap minat beli konsumen, hanya variabel citra toko yang berpengaruh secara signifikan pada minat beli konsumen terhadap produk makanan private label. Sementara itu, persepsi risiko, price consciousness, persepsi kualitas dan familiarity tidak memengaruhi minat beli konsumen terhadap produk private label. Selanjutnya, rak penyimpanan barang memengaruhi familiarity dan persepsi kualitas, persepsi risiko tidak memengaruhi price consciousness, citra private label memengaruhi persepsi risiko, kualitas servis memengaruhi citra private label, familiarity tidak memengaruhi persepsi kualitas, serta familiarity memengaruhi persepsi risiko.

Rekomendasi untuk penelitian selanjutnya yaitu dapat menambah variabel yang diuji. Berdasarkan hasil penelitian terdahulu, trust memengaruhi minat pembelian sehingga pada penelitian selanjutnya penting untuk menambahkan variabel trust untuk diuji pengaruhnya terhadap minat pembelian sebagai pengembangan model penelitian. Berdasarkan hasil temuan, citra toko yang paling memengaruhi minat pembelian. Oleh karena itu, konsumen dapat menilai suatu produk berdasarkan persepsi mengenai citra terhadap toko yang menjual produk tersebut. Citra tersebut dapat dilihat dari aspek penilaian terhadap lingkungan toko, kualitas pelayanan, kualitas produk yang dijual di toko secara keseluruhan serta bagaimana toko mampu menjaga dan menyimpan produk agar kualitasnya tidak menurun.
Variabel familiarity ditemukan berpengaruh signifikan terhadap persepsi risiko. Hal ini menunjukkan bahwa jika konsumen pernah mengetahui dan memiliki informasi mengenai produk private label maka akan mengurangi persepsi risiko terhadap produk tersebut. Oleh karena itu, penting bagi konsumen untuk mencari informasi awal mengenai produk agar tidak timbul keraguan-raguan dalam membeli. Beberapa informasi yang perlu dicari oleh konsumen yaitu berkaitan dengan komposisi dan nilai gizi secara sekilas untuk mengetahui gambaran kualitas produk yang ingin dibeli. Selain itu, konsumen juga perlu mencari informasi dari kerabat dan teman yang pernah berpengalaman mengonsumsi produk tersebut, membaca informasi-informasi yang tertera pada produk, serta mencari tahu terlebih dahulu informasi mengenai produk dari berbagai sumber seperti koran, media sosial, koran elektronik dan sebagainya.

\section{DAFTAR PUSTAKA}

Agrawal, J. Richardson, P. S., Grimm, P. E. (1996). The relationship between warranty and product reliability. Journal of Consumer Affaris, 30, 421-443.

Ailawadi, K. L., Keller, L. K. (2004). Understanding retail branding: conceptual insights and research priorities. Journal of Retailing, 80, 331342.

Alba, J. W., Hutchinson, J. W. (1987). Dimensions of consumer expertise. Journal of Consumer Research, 13, 411-454.

Anderson, E. W., Fornell, C., Lehmann, D. R. (1994). Customer satisfaction, market share, and profitability: findings from Sweden. Journal of Marketing, 58, 5366

Arslan Y., Gecti F., Zengin H. (2013). Examining peceived risk and its influence on attitudes: a study on private label consumers in Turkey. Asian Social Science 9, 158-166.

Bao, Y.C., Bao, Y.Q., Sheng, S.B. (2011). Motivating purchase of private brands: effect of store image, product signatureness, and quality variation. Journal of Business Research, 64, 220226.

Besra E., Kartini D., Hasan M. (2015). The role of retail image and customer trust on purchase intention of private label product. International Journal of 
Scientific \& Technology Research, 4, 215-218.

Brady, M. K., Cronin, J. J. (2001). Some new thought on conceptualizing perceived quality: a hierarchical approach. Journal of Marketing, 65, 34-49.

Brown, M. G., Lee, J. (1996). Allocation of shelf space: a case study of refrigerated juice product in grocery stores. Agribusiness, 12, 113-121.

Carrilat, F. A., Jaramillo, F., Mulki, J. P. (2009). Examining the impact of kualitas servis: a meta-analysis of empirical evidence. Journal of Marketing Theory and Practice, 17, 95-110.

Collins, D. C., Lindley, T. (2003). Store brand and retail differentiation: the influence of store image and store brand attitude on store own brand perceptions. Journal of Retailing and Consumer Services, 10, 345-352.

Dunia Industri (2015). Data Industri Minimarket, Supermarket, Hypermarket di Indonesia. Diambil dari http://duniaindustri.com/downloads/dataindustri-minimarketsupermarkethypermarket-di-indonesia/

Dhar, S. K., Hock, S. J. (1997). Why store brand penetration varies by retailer. Marketing Science, 16, 208-227.

Dodds, W., Monroe, K. B., Grewal, D. (1991). Effect of price, brand and private label information on buyer's product evaluation. Journal of Marketing Research, 28, 307-319.

Dursun, I., Kabadayi, E. T., Alan, A. K., Sezen, B. (2011). Store brand purchase intention: Effect of risk, quality, familiarity and store brand shelf space. International Strategic Management Conference, 24, 1190-1200.

Glynn, M. S., Chen, S. (2009). Consumerfactors moderating private label brand success: further empirical results. International Journal of Retail \& Distribution Management, 37, 896-914.

Grewal, D., Krishnan, R., Baker, J., Borin, N. (1998). The effect of store name, brand name and price discounts on consumer's evaluations and purchase intentions. Journal of Retailing, 74, 331352.

Matahari Department Store. (2012). Indonesia's Most Preferred Departement Store. Diambil dari http://www.indonesia- investments.com/upload/bedrijfsprofiel/2 30/matahari-department-store-annualreport-2012-Ippf-company-profileindonesia-investments.pdf

Dbs Group Research. (2015). Industri Focus ASEAN Grocery Retail. Diambil dari https://www.google.com/

Jin, B., Suh, Y. G. (2005). Integrating effect of consumer perception factors in predicting private brand purchase in a Korean discount store context. Journal of Consumer Marketing, 22, 62-71.

Kantar Wolrdpanel Total National Indonesia Fast Moving Consumer Goods. (2015). Kantar Worldpanel. Diambil dari: http://www.kantarworldpanel.com/id

Knight, D. K., Kim, E. Y. (2007). Japanese consumers' need for uniqueness: effects on brand perceptions and purchase intention. Journal of Fashion Marketing and Management, 11, 270-280.

Lichtenstein, D. R., Ridgway, N. M., Netemeyer, R. G. (1993). Price perceptions and consumer shopping behavior: A field study. Journal of Marketing Research, 30, 234-245.

Liljander V., Polsa P., Riel A. (2009). Modeling consumer responses to an apparel store brand: Store image as a risk reducer. Journal of Retailing and Consumer Services 16, 281-290.

Parasuraman, A, Zeithamal, V. A., Berry, L. (1988). SERVQUAL: a multile scale for measuring consumer perceptions of kualitas servis. Journal of Marketing, 49, 41-50.

Pemerintah Kota Bogor. (2016. Berita Kota Bogor 4 Maret 2016. Diambil dari http://kotabogor.go.id/index.php/show_p ost/detail/3014/Hasil-Sensus-EkonomiNyatakan Pertumbuhan-Ekonomi-KotaBogor-Terus-Naik\#.VwNzGnq4Ezs

Richardson, P., Jain, A. K., Dick, A. S. (1996). Household store brand proneness: A framework. Journal of Retailing, 72, 159-185.

Sheau, F. Y., Sun, M. L., Yu, G. W. (2012). Private label proneness. Effect of peceived risk, quality and familiarty. Australasian Marketing Journal 20, 4558.

Sinha, I., Batra, R. (1999). The effect of conscumer price consciousness on private label purchase. International 
Journal of Research in Marketing, 16, 237-251.

Stone, R. N., Gronhaug K. (1993). Perceived risk: future considerations for the marketing discipline. European Journal of Marketing, 27, 39-50.

Frontier Consulting Group. (2016). Top Brand Award Kategori Retail Hypermarket, Supermarket dan Minimarket. Diambil dari http://www.topbrand award.com/.

Vahie, A., Paswan, A. (2006). Private label brand image: its relationship with store image and national brand.

International Journal of Retail Distribution Management, 34, 67-84.
Vo, T. T. N., Nguyen, C. T. K. (2015). Factor influencing customer perceived quality and purchase intention toward private labels in the Vietnam Market: The moderating effects of store image. International Journal of Marketing Studies, 7, 51-63.

Wu, P. C. S., Yeh, G. Y. Y., Hsiao, C. R. (2011). The effect of store image and servive quality on brand image and purchase intention for private label brands. Australasian Marketing Journal, 19, 30-39.

Zimmer, M. R., Golden, L. L. (1988). Impression of retail stores: a content analysis of consumer image. Journal of Retailing, 64, 265-293. 